\title{
Notas Sobre a Noção de Caráter em Reich ${ }^{1}$
}

Notes on Reich's notion of character

João Rodrigo Oliveira e Silva Universidade Ibirapuera

Paulo Albertini

Universidade

de São Paulo

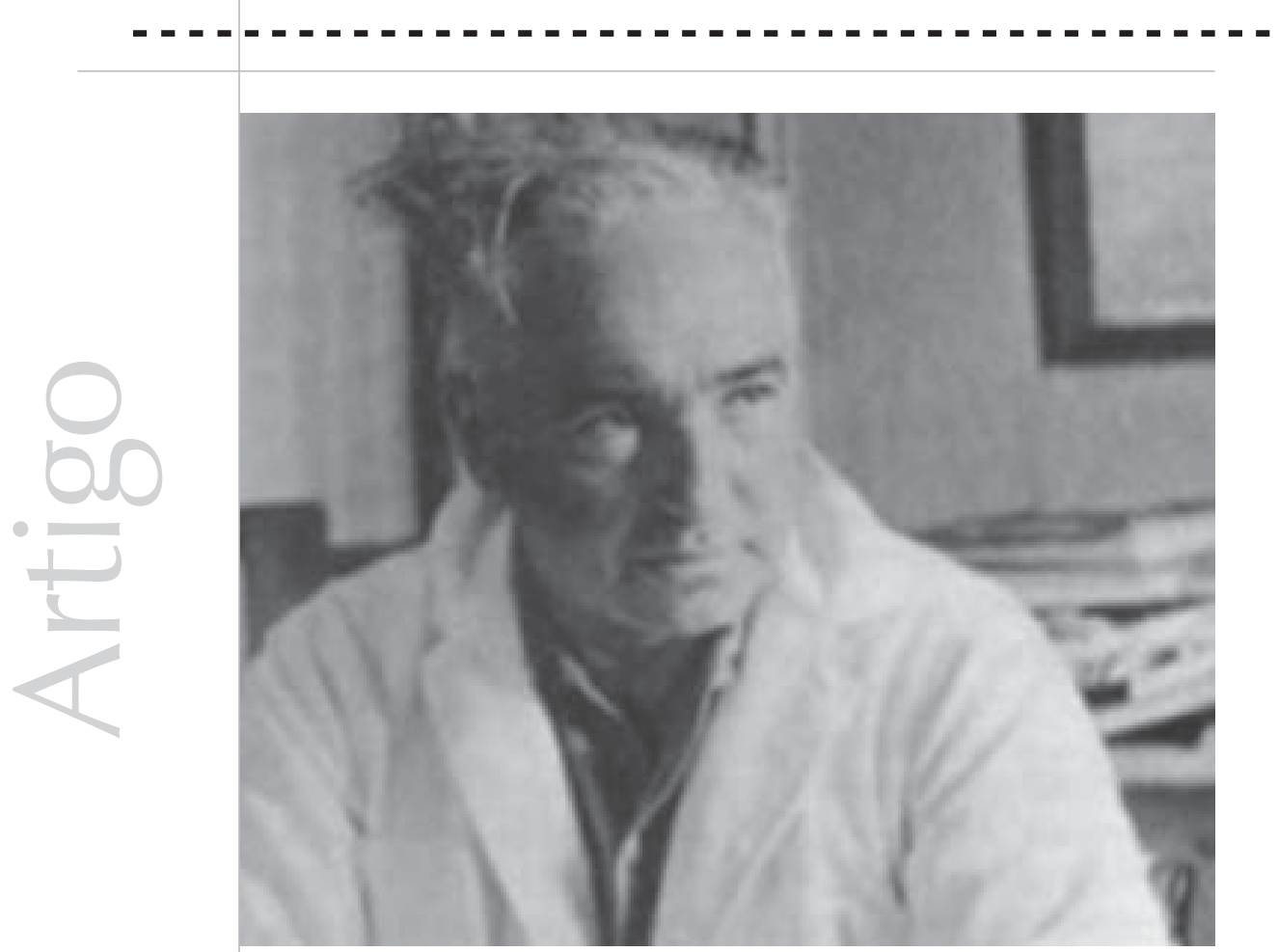




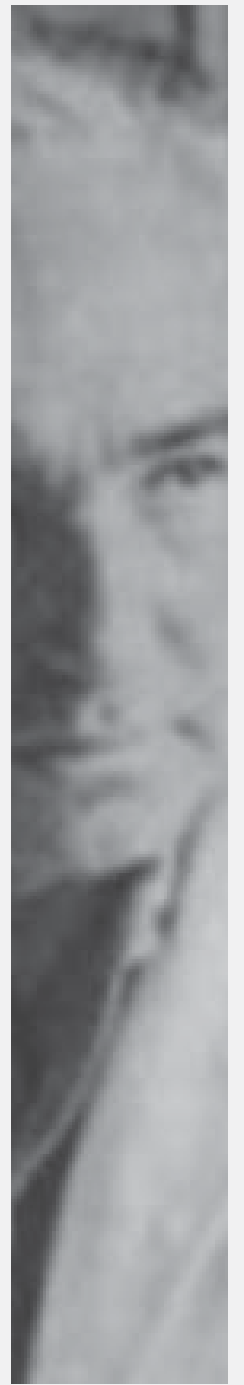

Resumo: Este estudo visa ampliar o conhecimento a respeito da fundamentação teórica das proposições do analista austríaco Wilhelm Reich. Investiga-se a noção de caráter presente em trabalhos reichianos da década de 1920 e início dos anos 1930. Foi sobretudo nessa época que o autor, então engajado no movimento psicanalítico, desenvolveu a conceituação de caráter e organizou a sua primeira técnica terapêutica, a análise do caráter. Em termos mais específicos, esta pesquisa busca: a) mostrar a vinculação entre as idéias reichianas de caráter com determinadas orientações presentes em escritos freudianos; b) contribuir para o esclarecimento da noção de caráter contida em textos reichianos publicados originalmente no período de 1922 a 1933. Dentre os pontos levantados nas abordagens de Freud e Reich, pode-se destacar a importância de se investigar o caráter como fonte de resistência. Já particularmente no domínio reichiano, merece relevo a aproximação efetuada pelo autor entre caráter e forma do comportamento. Palavras-chave: Reich, caráter, resistência, forma do comportamento.

Abstract: This article intends to extend the understanding of the theoretical foundations of the propositions made by the Austrian analyst Wilhelm Reich. It examines the notion of character as it appears in reichian work in the 1920's and in the beginning of the 1930's. It was mainly during this period of time that the author, then engaged with the psychoanalytical movement, developed the concept of character and organized his first therapeutic method: the character analysis. In more specific therms, this research aims: a) to present the connection between reichian reflections on character and certain approaches that appear in freudian writings; b) to contribute to the explanation of the notion of character as it is used in reichian texts published originally from 1922 to 1933. Among the subjects arising out of the study of Freud's and Reich's ideas on character, it can be emphasized the importance of investigating the character as a source of resistance. On the reichian particular ground, it ought to be pointed out the interrelation made by the author between character and ways of behavior.

Key words: Reich, character, resistance, ways of behavior.

Hoje, é fácil constatar a existência de psicólogos que trabalham tendo como referência as idéias desenvolvidas pelo analista austríaco Wilhelm Reich. Contudo, apesar de se observar certo incremento nas pesquisas científicas dedicadas às formulações desse autor, particularmente a partir dos anos 90, pode-se afirmar que ainda existe uma carência nesse domínio ${ }^{2}$.

Este trabalho se insere entre aqueles que visam contribuir para um maior esclarecimento a respeito da fundamentação teórica do pensamento de Reich. Ele investiga a noção de caráter presente em estudos reichianos da década de 1920 e início dos anos 1930. Foi sobretudo nessa época que o autor, então engajado no movimento psicanalítico, desenvolveu a conceituação de caráter e organizou a sua primeira técnica terapêutica, a análise do caráter. Em termos mais específicos, esta pesquisa busca: a) mostrar a vinculação entre as idéias reichianas de caráter e determinadas orientações presentes em escritos freudianos; b) contribuir para o esclarecimento da noção de caráter contida em textos reichianos publicados originalmente no período de 1922 a 1933.

Deve-se dizer que a noção de caráter é central na obra de Reich. Isso se dá por diversas razões. Em primeiro lugar, por ela estar
1 Trabalho é parte da Dissertação de Mestrado intitulada "O desenvolvimento da noção de caráter no pensamento de Reich". defendida pelo primeiro autor e orientada pelo segundo, no Instituto de Psicologia da Universidade de São Paulo, em 2001.

2 Um levantamento das dissertações e teses relacionadas ao pensamento reichiano defendidas até 0 ano de 2001 pode ser encontrado em Matthiesen (2001). 
presente nas três técnicas terapêuticas por ele organizadas: análise do caráter, vegetoterapia carátero-analítica e orgonoterapia; além disso, por ser uma noção que, no pensamento desse autor, perpassa a dimensão educacional e clínica, visto que as mesmas contribuem para a formação e transformação do caráter. Esse conceito articula, ainda, para Reich, as perspectivas psicológicas e sociopolíticas. As reflexões psicológicas ganham um matiz histórico, sociológico e político com base na marca que o caráter traz em si de sua época. Já as análises sociológicas ganham maior consistência psicológica ao remeterem à construção do caráter como um fator social e político relevante. Por fim, esse conceito carrega ainda uma dimensão ética, pois, como referência teórica e técnica, estrutura práticas e concepções sobre o ser humano.

Para cumprirmos os objetivos expostos, este estudo foi estruturado da seguinte forma: como entendemos que o enfoque de Reich a respeito do caráter está vinculado a uma série de formulações freudianas desenvolvidas, basicamente, até o livro O Ego e o Id (Freud, 1923/1976) - iniciaremos nosso trajeto com um levantamento a respeito dos usos do termo caráter na bibliografia freudiana até esse livro. A seguir, deter-nos-emos nas idéias de Reich sobre o caráter presentes nos seguintes trabalhos: Dois tipos narcisistas (Reich, 1922/1975), O caráter impulsivo: um estudo psicanalítico da patologia do ego (Reich, 1925/1975) e Análise do Caráter (Reich, 1933/ 1995). A escolha desses escritos se deu pelo fato de eles serem, no período, os mais significativos no que diz respeito à conceituação reichiana de caráter. Fecha este artigo um tópico dedicado às conclusões.

\section{O termo caráter em Freud}

Caráter é um termo que aparece disperso na obra freudiana. Não tem uma presença contínua e parece-nos difícil reconhecer, em Freud, uma teoria do caráter propriamente dita (diferentemente do que ocorre com a teoria das pulsões, por exemplo). Entretanto, há que se reconhecer que Freud concede, em alguns de seus textos, razoável importância a essa noção, o que provavelmente serviu de estímulo às investigações de seus seguidores, como Abraham, Jones, Ferenczi e o próprio Reich.

A primeira aparição do termo nos escritos freudianos se dá nos Estudos sobre a Histeria (1893-1895/1974). Relatando dois de seus casos (Frau Emmy von N. e Fraülein Elisabeth von R.), o autor faz menção ao caráter como um conjunto de traços ou características psicológicas pessoais, como, por exemplo, a desobediência, a ambição, a violência, a independência, a irritabilidade etc. Esse seria um uso descritivo e moral do vocábulo, bastante convencional, diga-se. No capítulo sete de A Interpretação de Sonhos (1900-1901/ 1972), Freud faz também uma pequena referência ao caráter, mas apenas para auxiliar seu esforço de construir um modelo do aparelho psíquico, sem formular acréscimos de qualquer elemento novo ao uso dessa noção.

Também no artigo O método psicanalítico de Freud (1904[1903]/1972), no qual o autor apresenta o método psicanalítico desde sua origem, no método catártico, até sua proposta de então, baseada na regra da associação livre, é possível observar a utilização do termo caráter no sentido mais convencional, moral, acrescida, porém, de uma outra perspectiva que vai repetir-se, de maneira mais desenvolvida, em escritos subseqüentes: a do caráter como fonte de resistência. No texto freudiano:

(...) se o médico tem que lidar com um indivíduo de caráter desprezível, logo perde o 
interesse que lhe torna possível penetrar profundamente na vida mental do paciente. Deformações de caráter muito arraigadas, traços de uma constituição realmente degenerada, mostram-se durante o tratamento como fontes de uma resistência que dificilmente pode ser superada (1904[1903]/ 1972, p. 262).

É no seu texto de 1905, Três Ensaios sobre a Teoria da Sexualidade (1905/1972), que elementos novos e ricos nos são fornecidos, permitindo uma considerável ampliação da noção de caráter. Nesses ensaios, quatro pontos merecem destaque no que diz respeito ao entendimento do caráter.

Primeiramente, o autor faz uso semelhante ao que já descrevemos, quando considera os traços de caráter atributos do sujeito, os quais, observados por um prisma convencional, distinguem, por exemplo, um caráter masculino de um caráter feminino - mantémse o sentido moral. Mais adiante, porém, faz uma comparação importante: entende algumas impressões profundas, inconscientes, derivadas do desenvolvimento sexual infantil, como determinantes do caráter nos indivíduos sadios e da sintomatologia nos neuróticos. Ora, dessa colocação, extraímos a primeira consideração de Freud sobre a formação do caráter - ligando-o ao desenvolvimento sexual infantil - mas também vemos um paralelo entre o caráter e o sintoma, como se parte da distinção entre eles derivasse do fato de o primeiro estar presente na saúde, ao passo que o último só se faria presente na neurose. Essa é uma relação que, veremos, vai transformar-se mesmo na obra de Freud.

Um terceiro ponto de destaque que esse artigo de Freud apresenta sobre o caráter surge quando o autor afirma que:
Aquilo a que chamamos 'caráter' de um homem constrói-se, numa boa medida, a partir do material das excitações sexuais, e compõese de pulsões fixadas desde a infância, de outras obtidas por sublimação, e de construções destinadas ao refreamento eficaz de moções perversas reconhecidas como inutilizáveis (1905/1996, p. 225).

Temos, nesse excerto, uma ponderação mais sofisticada sobre a formação do caráter e a apresentação de uma tese sobre sua matéria constitutiva. A tese, inequívoca, é de que o caráter se constrói pela transformação de excitações sexuais, especialmente as ligadas à disposição sexual perversa polimorfa da infância, pelas fixações, sublimações e formações reativas. Indo mais além, a solução psíquica da construção do caráter é vista favoravelmente como alternativa à perversão - que se desenvolveria caso essas excitações sexuais não fossem transformadas e se fortalecessem - e à neurose - que se instalaria caso essas excitações fossem totalmente contidas mediante recalque e encontrassem solução apenas por meio do sintoma. Novamente se situa o caráter mais próximo à normalidade do que à patologia.

O quarto ponto a observar sobre a consideração de caráter nesse texto abre uma ampla frente de investigação psicanalítica. Trata-se do reconhecimento de que é possível, em certos casos, observar a ligação entre o traço de caráter e um determinado componente erógeno, o que não quer dizer, necessariamente, que as tendências mais fortes da infância dominarão o caráter do adulto, até porque o processo de transformação de um componente erógeno em traço de caráter não é automático. De qualquer forma, essa constatação estimula a busca clínica de tal ligação. Alguns anos após
É no seu texto de 1905, Três Ensaios sobre a Teoria da Sexualidade (1905) 1972), que elementos novose ricos nos são fornecidos, permitindo uma considerável ampliação da noção de caráter. 
a publicação desse livro, Freud se debruçou sobre essa busca no artigo Caráter e erotismo anal (1908/1976a).

No referido artigo, o autor investiga a conexão existente entre alguns traços de caráter e o funcionamento, na infância, de determinados órgãos, ou, noutras palavras, a relação entre esses traços e o erotismo infantil. Com tal orientação, considerando a experiência com pacientes que apresentavam certos traços de caráter, como a ordem, a parcimônia e a obstinação, Freud começou a reconhecer a possibilidade de inferir que a dimensão erógena da zona anal fora especialmente forte na infância, o que se identificava por histórico de dificuldade de superação da incontinência fecal e por uma experiência infantil prazerosa na retenção das fezes, por exemplo. Dessa ligação, formula que esses traços de caráter surgiriam com o desaparecimento do erotismo anal, num processo de substituição, por meio tanto da sublimação desse erotismo quanto da formação reativa ao mesmo. Freud oferece como exemplo desse processo a obstinação, enquanto traço de caráter que representaria a sublimação do exercício de vontade própria da criança em reter as fezes, e a limpeza e a ordem como formações reativas derivadas do interesse pela imundice, próprio a essa fase. Desse exercício analítico, emerge um reforço da tese apresentada nos Três Ensaios...(1905/ 1996) sobre a formação do caráter. É o que fica expresso quando afirma, em Caráter e Erotismo Anal (1908/1976a), que: “(...) o caráter, em sua configuração final, se forma a partir dos instintos constituintes: os traços de caráter permanentes são ou prolongamentos inalterados dos instintos originais, ou sublimação desses instintos, ou formação reativa contra os mesmos ${ }^{3} "$ (p. 181).

No mesmo ano, Freud publicou o artigo Moral sexual civilizada e doença nervosa moderna (1908/1976b). Nesse trabalho, aponta o impacto, sobre a saúde e também sobre a constituição do caráter, das restrições morais à sexualidade. Nas palavras do autor:

Costuma-se dizer que a luta contra um instinto tão poderoso, com a acentuação de todas as forças éticas e estéticas necessárias para tal, 'enrijecem' o caráter. Isso pode ser verdadeiro no caso de algumas naturezas de organização muito favorável. Devemos admitir também que a diferenciação do caráter individual, tão marcante hoje em dia, só se tornou possível com a existência da restrição sexual. Contudo, na imensa maioria dos casos, a luta contra a sexualidade consome toda a energia disponível do caráter (...) (Freud, 1908/1976b, p. 201).

Esse trecho ilustra o sentido complementar que o artigo tem em relação às reflexões acerca da formação do caráter se comparado com o precedente. Enquanto em Caráter e Erotismo Anal (1908/1976a) Freud enfatiza a força do erotismo como elemento fundante da constituição do caráter, nesse último texto, o realce segue em direção inversa: seria a força da repressão moral da sociedade a marcar essa constituição. Que não se entendam tais considerações como antagônicas: elas simplesmente apontam para extremidades diferentes do conflito entre as pulsões sexuais e a repressão.

Até aqui, viu-se que Freud se deteve, inicialmente, no interesse descritivo e moral da noção de caráter, apontou o seu papel de resistência e, em seguida, focalizou a promissora relação entre o erotismo e o desenvolvimento do caráter. Já em 1916, sob o título Alguns tipos de caráter encontrados no trabalho psicanalítico (Freud, 1916/1974), o autor publicou um novo trabalho relacionado ao tema caráter. Nesse estudo, três tipos de 
caráter são descritos e ilustrados por meio da utilização de personagens da literatura. $\mathrm{O}$ primeiro congrega aqueles indivíduos que, sentindo-se, em certo ponto de suas histórias, vítimas ou sofredores de um destino infeliz, passam a considerar-se exceções, com direito a serem poupados das exigências desagradáveis da vida. Ilustra esse tipo Ricardo III, personagem de Shakespeare. O segundo caso seria o dos indivíduos "arruinados pelo êxito", que adoecem justamente em decorrência da realização de um desejo. Freud procurou explicar dinamicamente esse tipo ilustrando-o com as personagens de Shakespeare e Ibsen, Lady Macbeth e Rebecca (de Rosmersholm). O último tipo seria o dos criminosos cujas ações decorrem de um sentimento pré-existente de culpa.

Ainda nesse trabalho de 1916, Freud tece algumas observações sobre as dificuldades técnicas que esses tipos de caráter tendem a apresentar na clínica. Como ele não aprofunda muito a discussão técnica nesse texto, deixaa em aberto, fomentando sua necessidade. Vejamos um fragmento no qual o autor sinaliza a importância das resistências associadas ao caráter:

Quando um médico empreende o tratamento psicanalítico de um neurótico, seu interesse não se dirige, de modo algum, em primeiro lugar, para o caráter do paciente. Prefere saber o que significam os sintomas (...) Contudo, a técnica que ele é obrigado a seguir logo o compele a dirigir sua curiosidade imediata para outros objetivos. Observa que sua investigação se acha ameaçada por resistências erguidas contra ele pelo paciente, podendo o médico, com razão, encarar essas resistências como parte do caráter do paciente. Isso passa a adquirir a prioridade de seu interesse (Freud, 1916/1974, p. 351).
Vê-se, então, o reconhecimento de Freud de que o interesse psicanalítico não só pode, como deve voltar-se sobre o caráter em determinadas situações clínicas. Além disso, tal como já aparecera no trabalho $O$ método psicanalítico de Freud (1904[1903]/1972), apresenta-se a possibilidade de se pensar em resistências de caráter. Como veremos mais adiante, afiguram-se aí duas entradas significativas que Reich viria desenvolver.

Se o texto de 1916 marca claramente o campo da reflexão sobre a técnica da análise do caráter, é apenas em O Ego e o Id (Freud, 1923/1976) que os elementos de uma ponderação metapsicológica sobre o caráter se alinham efetivamente. Nesse trabalho, Freud conduz o leitor, gradativamente, a reflexões desveladoras das três estruturas psíquicas que vieram constituir sua chamada segunda tópica.

No primeiro capítulo do livro, retoma-se a perspectiva da primeira tópica, a saber, a divisão do aparelho psíquico entre três sistemas: inconsciente, pré-consciente e consciente. Nessa divisão, a instância mental chamada ego - responsável pelo controle da motilidade e pela conseqüente descarga das excitações para o mundo externo bem como pelo recalcamento de certas tendências - se ligava ao consciente. Em seguida, porém, demonstrada pelo próprio autor, a insuficiência dessa formulação o conduziu ao reconhecimento de que há também, no ego, uma significativa dimensão inconsciente. Tal insuficiência se revelara na sua consideração do inconsciente, que seria sempre o reduto de conteúdos recalcados; a essa altura, Freud passava a admitir a existência de uma importante parte não recalcada do inconsciente. 
Explorando essa idéia nos dois capítulos seguintes, Freud reformulou sua tópica. Principiou diferenciando o id do ego: o primeiro seria o manancial inconsciente e desconhecido de paixões, gradualmente modificado no contato com o mundo, em decorrência do que se originaria o ego, uma instância intermediária entre o id e a realidade externa, instância que busca "(...) aplicar a influência do mundo externo ao id e às tendências deste, e esforça-se por substituir o princípio de prazer, que reina irrestritamente no id, pelo princípio de realidade" (Freud, 1923/1976, p. 39).

Em seguida, o autor apresenta o ideal do ego, ou superego, como uma diferenciação mais tardia do ego, realizada com base em processos de identificação, cuja função é julgar, interditar e fornecer um ideal forjado por meio do prisma constituído com a interiorização das exigências e das interdições derivadas da resolução do complexo de Édipo.

É nesse ponto que Freud enuncia algumas considerações sobre o caráter. Embora elas não forneçam explicações definitivas sobre o conceito nem elevem sua eventual definição ao patamar de importância das instâncias acima referidas, tais considerações aportam elementos inéditos ao exame da formação do caráter. Assim, na primeira referência feita ao caráter, no trabalho mencionado, afirma: “(...) esse tipo de substituição [de uma catexia do objeto por uma identificação] tem grande parte na determinação da forma tomada pelo ego e efetua uma contribuição essencial no sentido da construção do que é chamado de seu 'caráter'" (Freud, 1923/1976, p. 43).

Aqui, recolhemos dois novos elementos. Primeiro, a observação de que o processo chamado de identificação participa da construção do caráter; segundo, a consideração de que o caráter está ligado ao ego, mais ainda, é o caráter do ego. São essas as principais contribuições do referido texto ao nosso propósito.

Quanto à primeira, destaque-se que, quando Freud apresenta a construção do superego a partir da diferenciação do ego, tem de reportarse ao processo de identificação como o modelo dessa diferenciação, ou alteração, do ego. E como se dá o processo de identificação? O modelo que Freud adota é semelhante ao que supõe ocorrer na melancolia, isto é, em seguida à perda de um objeto sexual, o ego introjeta as características desse objeto, facilitando o abandono do mesmo e se oferecendo ao id como um substituto. Esse processo remete à organização sexual da fase oral, quando a catexia de objeto e a identificação estão juntas, posto que a meta da pulsão é a incorporação ou absorção do objeto. Assim, face ao abandono de um objeto sexual, como o que necessariamente ocorre em relação aos pais na solução do complexo de Édipo, o ego se altera com base nas características do objeto abandonado.

O caráter, então, seria o conjunto resultante dessas modificações no ego. Ele seria, conseqüentemente, “(...) um precipitado de catexias objetais abandonadas (...)"(Freud, 1923/1976, p. 43), funcionando como um cemitério de relações objetais a atrair para si investimentos pulsionais. Evidentemente, o caráter não deve acolher quaisquer identificações, uma vez que elas podem oporse umas às outras, arriscando, em última análise, a própria integridade do ego. Assim, também o caráter passa a resistir ao retorno das catexias objetais, tornando-se mais fixo. Com isso, "(...) os efeitos das primeiras identificações efetuadas na mais primitiva 
infância serão gerais e duradouros" (Freud, 1923/1976, p. 45).

Agora, considerando as relações entre o caráter, o ego e o superego, veremos que o caráter se afigura justamente como a dimensão do ego erigida pelas diversas marcas que lhe foram impressas pelas identificações, atribuindo-lhe singularidade e, ao mesmo tempo, assinalando a história de suas perdas de objetos. No que diz respeito ao superego, arriscaríamos dizer que, no artigo mencionado, sua formação também se dá por meio de identificações; contudo, essas identificações se mantêm, de alguma forma, à parte, exercendo certo domínio sobre o ego, enquanto as alterações constitutivas do caráter são, pelo ego, incorporadas.

Tendo percorrido a bibliografia freudiana no que tange à noção de caráter até o Ego e o ld (1923/1976), traçamos os contornos do que, no conceito freudiano, pode ter desempenhado algum papel na formulação de Reich. Viu-se como Freud, partindo de um uso convencional, descritivo e moral do termo, começou a incorporá-lo ao interesse psicanalítico: primeiramente, como possível fonte de resistência, depois, investigando a relação entre caráter e erotismo e, também, apontando algumas situações técnicas desafiadoras marcadas pela presença de certos traços de caráter. Por fim, verificou-se como o autor chegou a dar lugar a essa noção na apresentação de sua segunda tópica, de modo que o caráter, além de estar relacionado, ou melhor, ser constituído pelo prolongamento ou transformação de pulsões parciais, é também, simultaneamente, fruto de identificações com objetos amorosos abandonados.

\section{Reich e o conceito de caráter}

Em 1922, apenas dois anos após ter sido formalmente aceito no movimento psicanalítico, Reich escreveu o trabalho intitulado Dois tipos narcisistas (1922/1975). Já nesse artigo, o jovem psicanalista faz suas primeiras referências ao termo caráter, ainda que apenas vinculadas à concepção de uma neurose de caráter.

Reich, em tal texto, aprova a distinção apresentada por Alexander no trabalho Complexo de Castração e Caráter (Alexander apud Reich, 1922/1975) entre neurose - na qual os sintomas estariam localizados e definidos - e neurose de caráter - na qual os sintomas estariam difusos, sem clara localização, e misturados ao conjunto do modo de ser do paciente. Mas, para além de acatar essa distinção, Reich elabora uma tese própria sobre a origem dessa diferença. Ele formula uma distinção entre os caminhos que conduzem à neurose ou a uma neurose de caráter: o tipo de investimento libidinal - no que diz respeito ao alvo desse investimento que está prejudicado. Em outras palavras, se a libido de objeto, ou seja, aquela parcela das pulsões sexuais que toma por alvo um objeto externo encontra-se mais intensamente perturbada, por exemplo, pelo recalcamento das pulsões sexuais objetais, há possibilidade de se desenvolver uma neurose com delineamento claro dos sintomas, separado do conjunto da personalidade e em estreita relação simbólica com o desejo recalcado e as pulsões em jogo. Porém, se a libido do ego, a parcela das pulsões que tomam o próprio ego por objeto, é que se encontra mais predominantemente perturbada, então os sintomas são difusos e extensos, impossíveis de serem separados do conjunto da personalidade. A diferença entre ambas, porém, coloca-se mais quantitativa que qualitativamente, sendo as respectivas características descritas correspondentes a configurações extremas, visto que,
Tendo percorrido a bibliografia freudiana no que tange à noção de caráter até o Ego e old(1923/1976), traçamos os contornos do que, no conceito freudiano, pode ter desempenhado algum papel na formulação de Reich. 
freqüentemente, o que se encontra é uma mistura de neurose sintomática e de caráter, em graus variados. Tanto é assim, que o próprio autor afirma: “(...) não há neurose, não importa quão claramente definida, sem traços de um distúrbio de toda a personalidade" (1922/1975, pp. 134-135).

Em seguida, Reich delineia algumas características típicas da clínica de pacientes com neuroses de caráter, no sentido em que utilizou o termo, contrastando ainda com os pacientes neuróticos (sintomáticos). Uma dessas características é a menor intensidade conjugada à maior demora no estabelecimento de uma transferência positiva, no caso dos pacientes com neuroses de caráter. Outra é a presença, muito freqüente, de uma transferência negativa inicial vigorosa, explícita ou latente, decorrente da dimensão ameaçadora que a análise assume para esses pacientes. Eles percebem a análise como uma castração, sendo o analista o inimigo a infligi-la. Como conseqüência desse processo, surgem sempre defesas (couraças) narcísicas que o analista deve habilidosamente penetrar. Aqui, vale observar que Reich, nesse texto, já utiliza o termo couraça, que, posteriormente, assumiu grande importância em sua obra.

Após ter delineado diferenças entre neurose de caráter e neurose, Reich, finalmente, passa a discorrer sobre os dois tipos de neurose de caráter ou os "dois tipos narcisistas" que intitulam o artigo. De forma sintética, tem-se que o primeiro tipo descrito congrega pacientes acometidos de sentimentos expressos de inferioridade, os quais encobrem ideal de ego e superego como sinônimos, em concordância, inclusive, com o uso freudiano dos termos em O Ego e o Id (Freud, 1923/1976). e principal objeto da libido o próprio ideal de ego. O segundo tipo contrasta com o primeiro: promove um narcisismo compensatório manifesto e sentimentos latentes de inferioridade decorrentes do complexo de castração inconsciente que, impedindo a construção de um ideal de ego, obteve compensação através de uma supervalorização do ego. É dessa supervalorização que extrai sua satisfação, por meio, por exemplo, de uma postura exibicionista.

Numa apreciação global, diríamos que, no trabalho em foco, Reich sinaliza pontos importantes que envolvem o tema caráter, sem, no entanto, explorar mais detidamente as implicações teóricas associadas a esses pontos. Assim, antes de mais nada, deve-se notar que o autor tende a empregar o termo caráter como um contraponto a sintoma. Se o último aparece na neurose, isolado e facilmente localizado, por exemplo, num comportamento, o primeiro, quando é usado numa expressão como neurose de caráter, agrega uma qualidade difusa à perturbação, envolvendo a totalidade do indivíduo. Contudo, essa dimensão difusa não é especialmente discutida nesse texto. Ademais, quanto à distinção apresentada, institui-se certo paradoxo: ao mesmo tempo em que o autor busca discernir neurose e neurose de caráter, noutro momento, ressalta que toda neurose traz uma dimensão "total" ou narcísica, que, a princípio, seriam as características determinantes de uma neurose de caráter; refaz-se, com isso, determinada unidade entre os dois tipos de neurose.

Além disso, a discussão das singularidades que essas neuroses de caráter criam, em termos da situação clínica, com suas couraças narcísicas e transferências negativas, é outro aspecto relevante desse trabalho, que acena para a 
abordagem das conseqüências técnicas da nova formulação sobre a neurose. Nesse sentido em particular, o esforço é coerente com a sugestão feita por Freud em Alguns Tipos de Caráter Encontrados no Trabalho Psicanalítico (1916/1974), de se explorarem as sutilezas técnicas da abordagem de uma neurose de caráter ou de uma resistência de caráter.

Por fim, pode-se dizer que, do conjunto das considerações que Reich faz nesse trabalho, não é possível ainda deduzir, de forma estruturada e fidedigna, o que ele chama de caráter, embora sua relação com o narcisismo, com a formação do ego e do ideal de ego, bem como com as resistências à análise, já se afigurem.

No percurso teórico reichiano, um outro marco para se investigar a noção de caráter é o livro O Caráter Impulsivo: um Estudo Psicanalítico da Patologia do Ego (Reich, 1925/1975). Nesse livro, o conjunto de elaborações mais afinado com a noção de caráter está presente nos dois primeiros capítulos. Nestes, Reich esboça o que entende por caráter, traz alguns elementos sobre sua formação, integrando-a ao processo de formação do superego e, por fim, dialoga com O Ego e o ld, (1923/1976) de Freud.

Em linhas gerais, de acordo com a concepção reichiana, o caráter impulsivo seria uma forma específica de caráter neurótico dominado pela pulsão, donde surge seu nome - impulsivo. Essa dominação ocorre quando a inibição da pulsão se deu de forma defeituosa, geralmente muito tardia e traumática, de modo que, no desenvolvimento do ego, ao invés de haver uma integração do superego ao conjunto do psiquismo, ele fica isolado. Diversas razões poderiam contribuir para esse isolamento: uma postura muito ambivalente dos pais em relação à repressão das pulsões das crianças, a ausência de modelos externos (parentais) para o superego, a alternância muito grande da apresentação de figuras ideais, entre outras.

A tese que Reich defende nesse texto é a de que, no processo de educação saudável, as pulsões infantis sejam parcialmente gratificadas e parcialmente reprimidas pelos pais, numa medida e numa forma tais que essa repressão seja suportada pela criança por amor aos pais (particularmente àquele que é responsável pela interdição) e, assim, incorporada como ideal de ego em seu psiquismo, proporcionando, desse modo, um desenvolvimento egóico integrado e dirigido à realidade. No caso do caráter impulsivo, a pulsão teria seguido muito tempo sem ser reprimida, fortalecendo as demandas pulsionais e o ego primitivo, estando impedido o desenvolvimento de tolerância à frustração, por um lado, e obstaculizada a constituição gradual de um ideal de ego, por outro. Frente a esse quadro, em dado momento, far-se-ia uma interdição com intensidade e violência brutais, desfavoráveis ao processo de assimilação e identificação com a figura repressora. Constitui-se, daí, não um superego fundido ao ego do indivíduo, como seria o usual, mas um superego isolado, composto de elementos da autoridade repressora, adotados de forma dissociada do ego. Assim, o que chama a atenção nesse escrito dos primeiros anos da produção reichiana é o fato de o autor advogar a necessidade de coerência e, em certa medida, de repressão no processo educativo, isso ao contrário da imagem de "plena liberdade" que tende a embalar e a uniformizar a leitura dos textos desse pensador.

Especificamente no que diz respeito à concepção de caráter, como dissemos, esse livro traz alguns elementos bastante 
relevantes. Logo na primeira frase, Reich aponta a ausência de uma teoria psicanalítica sistemática do caráter. Em suas palavras:

(...) no presente, nós não temos uma teoria psicanalítica do caráter que seja sequer parcialmente sistemática (...). O pré-requisito para uma caracterologia psicanalítica seria o conhecimento exato dos mais detalhados mecanismos do desenvolvimento psíquico, uma demanda que estamos longe de satisfazer (Reich, 1925/1975, p. 237).

Dessa forma, Reich destaca que não havia, nesse momento do pensamento psicanalítico, uma teoria estruturada e sistemática sobre caráter. Além disso, as reflexões mais avançadas, particularmente $O$ Ego e o Id (Freud, 1923/1980), indicavam que, para além das considerações sobre a importância do erotismo na constituição do caráter, o campo novo da Psicologia - ou metapsicologia - do ego surgia como a nova fronteira da teoria psicanalítica, promissora para o estudo do caráter. Para o autor, nem mesmo a coerência dos elementos da teoria do desenvolvimento sexual de então auxilia suficientemente a tarefa de uma compreensão caracterológica da personalidade, até porque “(...) as dinâmicas do ego são mais difíceis de compreender do que as dinâmicas do desenvolvimento sexual" (Reich, 1925/1975, p. 237).

Do ponto de vista do interesse terapêutico, Reich já se mostrava convicto da importância do entendimento sobre o caráter dos pacientes. Ademais, reconhecia que essa

5 Pensadas como a organização psíquica que impede determinado conteúdo inconsciente de se tornar consciente, ao mesmo tempo em que ela mesma, enquanto resistência, mantém-se inconsciente. importância já vinha sendo absorvida pela psicanálise, que “(...) deixou há muito de ser meramente uma terapia de sintomas; pelo contrário, vem-se transformando, constantemente, em uma terapia de todo o caráter" (p. 238). Isso se devia, em parte, à compreensão de Freud de que o fator crucial do trabalho analítico é a dissolução das resistências ${ }^{5}$, e não apenas a remissão dos sintomas. Reich dá ares definitivos a essa direção quando afirma que "(...) se alguém pretende alcançar recuperação genuína, na qual a recaída está fora de questão, então a análise do caráter deve substituir a análise de sintomas" (pp. 238-9).

Com base nesse primeiro apanhado de referências, já podemos elencar elementos para nossa reflexão. Reencontramos, aqui, como um marco da noção de caráter, a mesma distinção entre sintoma e caráter encontrada em Dois tipos narcisistas (Reich, 1922/1975). Essa diferenciação continua em destaque mesmo em textos posteriores do autor, e vemos que embasa parte das proposições técnicas por ele estabelecidas, a começar pela própria direção do foco da análise para o caráter dos pacientes e o reconhecimento da superioridade da análise do caráter, em termos de eficácia clínica, se comparada à análise de sintomas. Desse modo, parece-nos justo colocar em relevo esse contraste, ou contraponto, entre sintoma e caráter como uma relação cuja dinâmica seguirá atribuindo significado a este último.

Ainda no primeiro capítulo do trabalho em exame, Reich faz outras três observações, as quais, embora um pouco isoladas e descontínuas, alimentam nossa investigação. A primeira delas é tecida quando o autor comenta que a análise do caráter deve, necessariamente, exercer mais a análise das ações e dos comportamentos do que se faria usualmente, numa "análise da memória" (1925/1975, p.239), isto é, numa análise voltada para as lembranças do paciente. Fundamenta essa proposição seu 
entendimento de que as peculiaridades do caráter encontram sua expressão privilegiada nas ações. Dessa consideração, engendra-se mais um laço, desta vez, entre caráter e ação, o que, do ponto de vista técnico, cria certas dificuldades, posto que “(...) as ações são pouco adaptadas à interpretação genético-analítica sem recordações subseqüentes ou sem ao menos uma reconstrução analítica das fontes do comportamento" (Reich, 1925/1975, p. 239). De qualquer modo, essa constatação de Reich era compartilhada por outros autores, como Ferenczi e Rank, que também vinham buscando novas maneiras de intervenção clínica capazes de dar conta dessa dimensão recémincorporada à análise.

A segunda observação de interesse para nós é bastante mais específica e corresponde a uma equivalência que, a certa altura, Reich propõe entre o caráter e a personalidade inteira. Não desenvolve, sequer tematiza essa aproximação, mas, uma vez que garimpamos, nesse texto, elementos de proveito para a nossa pesquisa, podemos empenhar-nos no vislumbre do que essa equivalência nos oferece. A nosso ver, ela confirma, a despeito de haver nessa explicação certa circularidade, o que era expresso na distinção entre sintoma e caráter, a saber, que a este último cabe a dimensão totalizante e ampla de algo que podemos chamar de personalidade.

A última dessas considerações consiste num elogio ao livro de Freud, O Ego e o Id (1923/ 1976), reconhecendo-o como um marco da bibliografia psicanalítica na área dos estudos sobre o caráter. A partir desse reconhecimento, Reich arrola os pontos que considera serem indicações derivadas desse artigo, importantes na explicação da formação do caráter. E que pontos são esses? O autor cita como significativos: as atitudes dos pais assimiladas pela criança como ideal de ego positivo ou negativo; o padrão de ideal de ego que foi principalmente seguido, o do genitor de mesmo sexo ou de sexo oposto; o estágio do desenvolvimento da libido no qual as identificações se deram; o quanto do ideal do ego pode ser realizado no ego-real ${ }^{6}$ e sob quais condições, e a atitude do ego-prazer ${ }^{7}$ frente às primeiras identificações. Esses pontos vão servir ao longo de todo O caráter impulsivo... (Reich, 1925/1975) como referências permanentes para avaliar a formação do caráter e do superego nos casos estudados pelo autor.

No segundo capítulo, Reich prepara-se com vistas a apresentar o quadro clínico que chama de "caráter impulsivo" e, para tanto, formula uma ponderação em torno da conceituação de caráter. Nesta, afirma que vinha usando indiscriminadamente expressões como caráter impulsivo e neurose de caráter e seria necessário, então, realizar um esforço para esclarecer esses termos. Tal esclarecimento é difícil, segundo o autor, porque, em geral, tratase de modo muito vago o conceito de caráter. Diante disso, assume ele próprio uma definição, sendo esta uma das raras passagens em que Reich interrompe o fluxo de seu pensamento dedicando-se a explicações terminológicas. No texto:

(...) nós podemos definir 'caráter' como a atitude psíquica particular em direção ao mundo externo específica a um dado indivíduo. Isso é determinado pela disposição e pela experiência no sentido da 'série complementar' (Ergänzungsreihe) de Freud. Assim, nós consideramos tipos de caráter neurótico os indivíduos que apresentam desvios mais ou menos amplos em relação a uma norma de comportamento ajustado à realidade, tanto sexual quanto cultural, bem como em relação ao ajustamento social (1925/ 1975, p. 250).
(...) nós podemos definir 'caráter' como a atitude psíquica particular em direção ao mundo externo específica a um dado indivíduo.
6 Nesse texto, ao falar em ego-real, Reich se refere à soma dos elementos do ideal do ego efetivamente assimilada e, digamos assim, realizada, acrescida, nos adultos, dos impulsos sexuais dirigidos à realidade, sem que estejam em conflito com o superego.

7 No trabalho em exame, Reich emprega ego-prazer e ego-pulsão como sinonimos referentes ao primitivo ego do bebê, anterior às identificações $e$ à constituição do superego. Compóe-se “... inteiramente de tendências pulsionais de natureza sexual e destrutiva" (Reich, 1925/1975, p. 301); inclui tudo que é prazeroso e estranha tudo que é desconfortável. 
Nesse excerto, Reich divide a determinação do caráter entre a disposição e a experiência, de modo que há complementaridade e relação inversa entre esses fatores. Se há forte disposição endógena, o peso da experiência é menor, e vice-versa. Ele não renega nem uma dimensão nem outra, confiando a determinação do caráter à relação entre elas, tendo por base a noção freudiana de série complementar. Já a avaliação da neurose como um desvio de uma norma de ajustamento sexual, cultural e social é, a nosso ver, uma consideração bastante discutível no que concerne à natureza da neurose. É necessário, aqui, pontuar que, na seqüência da obra reichiana, o ajustamento, ou a adaptação, não vieram estabelecer-se como critérios de saúde psíquica; ao contrário, Reich muito combateu essa visão. Um exemplo desse combate pode ser encontrado no trabalho Escuta, Zé Ninguém (Reich, 1948/1974), uma crítica mordaz à patologia da normalidade.

Mais adiante, o autor procura esmiuçar sua definição. Recorre novamente à distinção entre sintoma neurótico e caráter neurótico de modo bastante mais refinado, desta vez. Afirma ele:

O sintoma neurótico localizado corresponde diretamente às áreas parciais da personalidade que foram "fixadas" em um estágio ou outro, enquanto o caráter neurótico é sempre uma expressão da atitude total correspondente à fixação. Assim, a fixação (e o conflito psíquico resultante dela) irá sempre exibir simultaneamente dois modos de expressão: primeiro, o sintoma neurótico particularmente correspondente a ela (por exemplo, vômito histérico como expressão de uma fixação oralgenital) e segundo, o caráter neurótico que
Vê-se que Reich considera sintoma e caráter neuróticos como expressões de uma fixação no âmbito do desenvolvimento psicossexual, o que ainda não havia enfatizado nesse livro. A diferença entre eles aparece em sua amplitude: enquanto o sintoma encontra-se diretamente ligado a essa fixação, podendo ser localizado em um comportamento isolado, como o vômito a que o autor se refere, o caráter, por sua vez, corresponde às alterações totais que tal fixação provoca na personalidade, sendo impossível localizá-las em um comportamento, apenas. É notável também que a fixação sempre vai expressar-se simultaneamente por meio do caráter e do sintoma, criando uma indissociabilidade entre ambos. Deve-se notar que, ao pensar no caráter como uma expressão abrangente das fixações parciais na personalidade, Reich criou condições para colocá-lo como base do sintoma neurótico, o que implica conceber a neurose sintomática como sendo sempre, em termos mais amplos, uma neurose de caráter. Numa apreciação global, pode-se afirmar que o livro O caráter impulsivo... (1925/1975) contém uma série de contribuições ao tema de nosso estudo. Um esboço mais claro da noção de caráter começa a impor-se: algumas idéias já presentes no artigo Dois tipos narcisistas (1922/1975), como a distinção entre caráter e sintoma, são mais desenvolvidas, e, além disso, a ação, a forma de expressão do comportamento, passa a ser vista como um meio privilegiado de conhecimento a respeito do caráter. Contudo, o autor pouco alude às implicações técnicas desses desenvolvimentos teóricos; tais implicações serão intensamente focalizadas no texto que veremos a seguir.

Ainda integrando os quadros da Associação Psicanalítica ${ }^{8}$, em 1933, Reich publicou o seu trabalho mais desenvolvido sobre o tema caráter: o livro Análise do Caráter. A edição 
original dessa obra, contendo um prefácio e doze capítulos, reunia artigos de 1926 até 1933 e, em linhas gerais, sintetizava as orientações técnicas formuladas por Reich durante o seu envolvimento institucional com a psicanálise. O texto é dividido em duas partes: a primeira, os seis primeiros capítulos, compõem uma discussão sobre a técnica psicanalítica; a segunda, do sétimo ao décimo segundo, aborda a teoria da formação do caráter. Se podemos identificar uma intenção em Análise do Caráter (Reich, 1933/1995), trata-se de extrair, da experiência analítica acumulada, as lições que permitissem a formulação de preceitos técnicos amplos e universais, a fim de orientar a apreciação de casos individuais. Logo, podemos dizer que esse é um livro de finalidade técnica.

Pode-se afirmar que Reich não estava sozinho nesse caminho de reflexão e reformulação da técnica psicanalítica. Ferenczi e Rank já buscavam, antes dele, rever a técnica com a ousadia que levaria ao desenvolvimento das inovadoras propostas de tais autores - a técnica ativa que Ferenczi propõe em $1919^{9}$ e a terapia ativa idealizada por Rank em $1926^{10}$. Não é possível, portanto, dizer que, nas décadas de 1920 e 1930, a psicanálise já dispusesse de preceitos técnicos amplos e consensuais, como explica o comentador da obra reichiana Roger Dadoun:

Quando Reich elabora os conceitos de análise caracterial e suas modalidades de intervenção (...), a psicanálise, por estranho que pareça, não dispunha de uma verdadeira estratégia terapêutica. Os poucos princípios propostos por Freud, aprofundados e refinados por analistas como Abraham, Rank ou Ferenczi regra de associação livre, leitura e interpretação do material inconsciente, especialmente onírico, transferência dos afetos ao psicanalista, tomada de consciência - configuram um marco bastante impreciso, dentro do qual são postos à prova todos os tipos de táticas pessoais (Dadoun, 1991, p. 100).

É inevitável que se levante a pergunta: de que forma esse movimento e essa intenção de busca de definição da técnica ótima se relacionam com a noção de caráter? Ora, justamente essa noção vai ser mais rigorosamente exigida devido a um determinado desenvolvimento que a técnica segue. Esse desenvolvimento diz respeito ao fato de que, progressivamente, o enfoque clínico vai dirigir-se do sintoma, entendido como algo mais restrito e isolado, para o caráter, concebido como uma dimensão total e ampla.

Essa direção, já esboçada em Freud, principalmente em Alguns Tipos de Caráter Encontrados no Trabalho Psicanalítico (1916/ 1974), e em Reich, está afinada com a crítica a uma clínica debruçada apenas sobre os sintomas (e também sobre a transferência positiva) e segue para o elogio a um trabalho cujo esforço se dirige à análise das transferências negativas e a todas as outras formas de resistências. Isso leva, por fim, à sua proposta de análise do caráter, sendo ele pensado também como uma resistência, e das mais importantes. Com essa orientação, salientou-se a importância de pensar sobre o que seja mesmo o caráter e sobre como ele se forma nas tramas inconscientes que constituem o homem, sujeito da psicanálise. Como vimos, já no artigo Dois tipos narcisistas (1922/1975) e, de maneira mais acentuada, no livro O caráter impulsivo... (1925/1975), Reich apontara a relação entre o caráter e resistência. Mesmo assim, a proporção que Análise do Caráter (1933/1995) dá à exploração do significado do caráter como resistência é
9 Segundo Haynal (1995), Ferenczi “(...) supõe que o analista possa ser capaz de abandonar sua posição, dita de 'receptividade passiva', para propor ao paciente, por exemplo, fazer uma experiência de frustração (interdição de um gesto, de um movimento), cujo objetivo é assegurar que as tensões habitualmente descarregadas pela motilidade possam ter acesso à análise" (p. 19).

10 De acordo com Roudinesco (1998), a terapia ativa de Otto Rank preconizava "(...) tratamentos curtos e limitados previamente no tempo, assim como um recentramento no presente: ao invés de sempre reconduzir o paciente à sua história passada e ao seu inconsciente (...), Rank julgava preferivel solicitar a vontade consciente deste e aplicá-la à situação presente, a fim de estimular o seu desejo de cura (...)" (p. 643). 
inédita. Para o autor, o caráter, ou seja, a dimensão total e ampla das atitudes individuais em relação ao mundo, "trabalha", na situação analítica, no sentido de evitar que certos conflitos e sentimentos inconscientes se tornem conscientes. E como o caráter, como resistência, se manifesta?

Ao abordar a manifestação do caráter como resistência, Reich retoma outro aspecto que enunciara antes: as resistências de caráter ligarse-iam à forma dos comportamentos, aos pequenos traços de caráter que, revelando dimensões resistentes à análise, davam novas possibilidades interpretativas ao psicanalista. No texto:

Certas considerações clínicas obrigam-nos a designar como "resistências de caráter" um grupo particular de resistências que encontramos no tratamento de nossos pacientes. Estas derivam seu caráter especial não de seu conteúdo, mas dos maneirismos específicos da pessoa analisada [grifos do Reich] (1933/1995, p.53).

Assim, o que marca essas resistências de caráter é o fato de aparecerem e operarem não por algum conteúdo ideativo isolado, mas por modos de agir próprios da pessoa, que carregam em si, de forma inconsciente, tendências resistentes e defensivas. Essa direção define o caráter como o conjunto de maneirismos, de modos de agir do homem, os quais, na análise, cumprem uma função de resistência.

Vale destacar que, ao falar em maneirismos, Reich não está concebendo comportamentos excêntricos ou descolados da totalidade da pessoa. Para ele, o caráter é “(...) o modo de existir específico de uma pessoa (...)" (1933/ 1995, p. 56), ou ainda o “(...) modo típico de reagir (...)" (p.150). Vemos, aqui, o caráter delimitado como um elemento individual e distintivo, tal qual aparece em $O$ caráter impulsivo... (Reich, 1925/1975). Assim, pensado como modo de agir de um indivíduo, o caráter se distancia ainda mais da noção de sintoma, pois, além de, diferentemente deste, não ser localizado e isolado num evento específico (como uma conversão histérica ou uma idéia obsessiva), também se notabiliza por não ser estranho ao paciente (egodistônico); o caráter consiste justamente no que lhe é mais próprio e particular (egosintônico). É sua forma de se comportar.

Apresenta-se, portanto, um quadro mais elaborado da noção de caráter para esse autor. Tomamos o conceito como o conjunto de atitudes e maneiras de agir de um indivíduo, que o singulariza e identifica, podendo operar, de forma inconsciente, como resistência à emergência de conflitos inconscientes e também como resistência à análise. Porém, ao identificar o caráter com a forma do comportamento, Reich desloca a técnica psicanalítica, em termos de foco, do conteúdo narrativo para os modos de sua apresentação, o que é uma mudança significativa decorrente dessa reorganização da noção de caráter. Diz o autor:

A resistência de caráter não se expressa em termos de conteúdo, mas de forma: o comportamento típico, o modo de falar, andar, gesticular, e os hábitos característicos (como o indivíduo sorri ou escarnece, se fala de maneira coerente ou incoerente, o quanto é polido e o quanto é agressivo). (...) O indício da resistência de caráter não está naquilo que o paciente diz e faz, mas no modo como fala e age. Também não está no que ele revela em sonhos, mas no modo como ele censura, distorce, condensa etc. (...). A resistência de caráter permanece a mesma no mesmo 
paciente, independente do conteúdo [grifos do Reich] (1933/1995, p.59).

Ilustrando essa mudança de foco, um psicanalista e ex-paciente de Reich, Oliver S. English, nos conta, sobre a postura daquele como psicanalista, em 1929, o seguinte:

Foi por essa época que me lembro do Dr. Reich utilizando seu interesse em outras apresentações da personalidade além das verbais. Por exemplo, ele iria freqüentemente chamar minha atenção para a monotonia de meu tom de voz enquanto eu associava livremente. Ele também chamaria atenção para minha posição no divã e me lembro particularmente que ele confrontou-me com o fato de que, ao entrar e sair do consultório, eu não me dirigia para um aperto de mãos com ele, como era costume tanto na Áustria como na Alemanha (English, 1977, p. 241).

Nessa citação, percebemos o impacto dessa reformulação conceitual dentro da clínica, na direção que leva à análise do caráter. Ora, se, no contexto analítico, o caráter opera com função de resistência à análise, então, do ponto de vista mais técnico, essa função do caráter exige que ele seja, em primeiro lugar, submetido à análise para que esta tenha condições de se realizar e não apenas parecer realizar-se. Tal discriminação, que visa instaurar verdadeiramente as condições de análise, é crucial para Reich. O que ele descobre é que, pela análise do caráter, o caminho para a análise dos significados inconscientes vai sendo espontaneamente aberto, pois o caráter traz em si o registro de sua constituição histórica pulsional e defensiva.

Ainda frente à questão sobre a função defensiva do caráter na estrutura psíquica do homem, Reich remete-se, inicialmente, à sua localização original. Para ele, tal como postulou
Freud em O Ego e o Id (1923/1976), o ego, do qual o caráter é parte, se situa entre as demandas pulsionais do id, exigentes e imperativas, e o mundo externo. Assim, dada essa posição, o caráter do ego teria a função de defendê-lo das exigências de um lado e do outro, protegendo-o, simultaneamente, da angústia decorrente desse conflito. Ao pensar dessa maneira, o autor concebe o caráter como um "muro de proteção" que absorve o impacto das exigências do id e do mundo externo sobre o ego. É por isso que, na situação de análise, o caráter, logo que sinta a aproximação de alguma ameaça (vinda de fora ou de dentro), passa a exercer sua função de defesa, impedindo, por exemplo, que conflitos inconscientes potencialmente desestabilizadores do equilíbrio do ego se tornem conscientes.

De acordo com Reich, o modo pelo qual o caráter defende o ego é o enrijecimento de sua forma, ou seja, a adoção incondicional, estereotipada e crônica de um modo de se comportar, de se mover etc, constituindo o que o autor chama de couraça de caráter ${ }^{11}$. A couraça protege o ego, só que, ao mesmo tempo, diminui "(...) a habilidade do ego para agir e sua liberdade de movimentos" (Reich, 1933/1995, pp. 192-193), restringindo a capacidade de satisfação sexual e intensificando, pela estase de libido, os conflitos que, inicialmente, buscava evitar. Assim, discorrendo sobre a função defensiva do caráter, Reich conceitua:

O caráter consiste numa mudança crônica do ego que se poderia descrever como um enrijecimento. Esse enrijecimento é a base real para que o modo de reação característico se torne crônico, cuja finalidade é proteger o ego dos perigos internos e externos. Como uma formação protetora que se tornou crônica, merece a designação de "encouraçamento",
De acordo com

Reich, o modo pelo qual o caráter defende o ego é o enrijecimento de sua forma, ou seja, a adoção incondicional, estereotipada e crônica de um modo de se comportar, de se mover etc, constituindo o que o autor chama de couraça de caráter.
11 A idéia de que o caráter possa enrijecer-se ou encouraçar aparece também em Ferenczi e Adler. Ferenczi (1930/1992) utiliza, inclusive, metáfora equivalente para indicar essa situação falando em "carapaça" ao descrever uma resistência estereotipada de caráter. 
pois constitui, claramente, uma restrição à mobilidade psíquica da personalidade como um todo [grifos do Reich] (1933/1995, p. 151).

Cabe notar que, ao atribuir ao caráter a condição de defesa, Reich o considera uma abrangente estratégia. Não se trata, portanto, de um mecanismo de defesa específico, mas de algo mais vasto, que se diferencia dos mecanismos de defesa de forma semelhante àquela com que se diferencia dos sintomas - pela sua amplitude.

\section{Conclusão}

Retomando os objetivos norteadores deste trabalho, podemos afirmar, quanto ao primeiro (aquele que trata da vinculação das idéias reichianas sobre o caráter com determinadas orientações presentes em escritos freudianos), que parte nuclear da teorização reichiana tem sua base fundada em idéias freudianas. Senão vejamos: a) a leitura reichiana do caráter como possível fonte importante de resistência já havia sido sugerida por Freud no artigo $O$ método psicanalítico de Freud (1904[1903]/1972) e, de forma mais completa, em Alguns Tipos de Caráter Encontrados no Trabalho Psicanalítico (1916/1974); b) o entendimento reichiano de que o caráter está associado às transformações das excitações sexuais é de origem freudiana; c) a larga utilização, nas formulações reichianas sobre o caráter, do modelo da chamada segunda tópica do texto freudiano O Id e o Ego (1923/1976).

Com relação ao segundo objetivo (aquele que visa contribuir para o esclarecimento da noção de caráter contida em textos reichianos publicados originalmente no período de 1922 a 1933), podemos dizer que é, sobretudo, a aproximação entre caráter e defesa que ajuda a compreender a perspectiva reichiana nesse domínio, ou seja, se procurarmos incluir essa dimensão defensiva à concepção acumulada que temos do caráter, veremos que seus diversos significados se articulam coerentemente: o caráter está proposto como a dimensão total das atitudes individuais que singularizam e identificam o indivíduo por meio da forma como essas atitudes se apresentam. O conjunto unificado dessas atitudes traz, como que decantada nas mesmas, a história de sua constituição e seus elementos constituintes. Ao mesmo tempo, cumpre, permanentemente, a tarefa de proteger o ego da desintegração e da angústia provocadas por sua localização intermediária entre o id e o mundo externo. Frente a isso, o caráter tem a possibilidade de apresentarse mais rígido (encouraçado) ou mais flexível. É por seu significado defensivo que o caráter, na análise, pode vir a consistir uma forte resistência ao trabalho analítico.

Por fim, numa apreciação global, é possível afirmar que a reflexão de Reich sobre o caráter, depois de um início ainda incipiente no artigo Dois tipos narcisistas (1922/1975) e de algum desenvolvimento em $O$ caráter impulsivo... (1925/1975), ganha contornos mais nítidos no livro Análise do Caráter (1933/ 1995). Vale lembrar que, mesmo após 1933 , quando já se anuncia o afastamento de Reich do movimento psicanalítico, a noção de caráter continua tendo importância significativa em seu pensamento e prossegue sendo esmiuçada a partir das novas referências técnicas que esse autor elabora. A apresentação desse desenvolvimento posterior, porém, excede o objetivo do presente artigo e permanece como uma sugestão para posteriores investigações. 


\section{João Rodrigo Oliveira e Silva}

Professor da Universidade Ibirapuera e

Professor do Instituto Sedes Sapientiae.

Mestre em Psicologia pela Universidade de São Paulo Rua Matheus Grou, 566. CEP: 05415-040. Pinheiros, São Paulo, SP. Tel: (0-11) 30313082 e-mail: jo.rodrigo@ig.com.br

\section{Paulo Albertini}

Professor Doutor do Instituto de Psicologia da Universidade de São Paulo.

Doutor em Psicologia

Rua José Getúlio, 506, apto 81-A. CEP: 01509-000. Aclimação,

São Paulo, SP. Tel: (0-11) 32720658 e-mail: albertin@usp.br

Recebido 05/01/04 Reformulado 13/05/05 Aprovado 30/09/05

DADOUN, R. Cem Flores para Wilhelm Reich. São Paulo: Moraes, 1991

ENGLISH, O. S. Some Recollections of a Psychoanalysis with Wilhelm Reich: September 1929 - Apr. 1932. Journal of the American Academy of Psychoanalysis. s.I., v.5 (2), 1977, pp. 239-253.

FERENCZI, S. O Tratamento Psicanalítico do Caráter. In Psicanálise IV. São Paulo, Martins Fontes, (1930) 1992, pp. 215-221.

FREUD, S.; BREUER, J. Estudos sobre a Histeria. In Edição Standard das Obras Psicológicas Completas de Sigmund Freud, v. II. Rio de Janeiro, Imago, (1893-1895) 1974, pp. 37-363.

. A Interpretação de Sonhos (parte II). In Edição Standard das Obras Psicológicas Completas de Sigmund Freud, v. V. Rio de Janeiro, Imago, (1900-1901) 1972, pp. 361-725.

O Método Psicanalítico de Freud. In Edição Standard das Obras Psicológicas Completas de Sigmund Freud, v. VII. Rio de Janeiro, Imago, (1904-1903) 1972, pp. 257-262.

Três Ensaios sobre a Teoria da Sexualidade. In Edição Standard das Obras Psicológicas Completas de Sigmund Freud, v. VII. Rio de Janeiro, Imago, (1905) 1972, pp. 129-250.

Caráter e Erotismo Anal. In Edição Standard das Obras Psicológicas Completas de Sigmund Freud, v. IX. Rio de Janeiro, Imago, (1908) 1976a, pp. 175-181.

. Moral Sexual 'Civilizada' e Doença Nervosa Moderna. In Edição Standard das Obras Psicológicas Completas de Sigmund Freud, v. IX. Rio de Janeiro, Imago, (1908) 1976b, pp. 187-208.

Alguns Tipos de Caráter Encontrados no Trabalho Psicanalítico. In Edição Standard das Obras Psicológicas Completas de Sigmund Freud, v. XIV. Rio de Janeiro, Imago, (1916) 1974, pp. 351-377.
O Ego e o ld. In Edição Standard das Obras Psicológicas Completas de Sigmund Freud, v. XIX. 2. ed. Rio de Janeiro, Imago, (1923) 1976, pp. 23-76.

HAYNAL, A. A Técnica em Questão: Controvérsias em Psicanálise: de Freud e Ferenczi a Michael Balint. São Paulo: Casa do Psicólogo, 1995.

JONES, E. Vida e Obra de Sigmund Freud. Rio de Janeiro: Zahar, 1979.

LAPLANCHE, J.; PONTALIS, J-B. Vocabulário da Psicanálise. São Paulo: Martins Fontes, 1983.

MATTHIESEN, S. Q. A Educação em Wilhelm Reich: da Psicanálise à Pedagogia Econômico-sexual. Tese de Doutorado em Educação. Universidade Estadual Paulista, Marília, 2001.

REICH, W. Two Narcissistic Types. In Early Writings, v. 1. New York: Farrar, Straus and Giroux, (1922) 1975, pp. 133-142.

. The Impulsive Character: a Psycoanalytic Study of Ego Pathology. In Early Writings, v. 1. New York, Farrar, Straus and Giroux, (1925) 1975, pp. 237-332

. Análise do Caráter. 2. ed. São Paulo: Martins Fontes, (1933) 1995.

. Escuta, Zé Ninguém. Lisboa/Santos: Martins Fontes, (1948) 1974

ROUDINESCO, E.; PLON, M.Dicionário de Psicanálise. Rio de Janeiro: Jorge Zahar, 1998.

WAGNER, C.M. Freud e Reich: Continuidade ou Ruptura? São Paulo: Summus, 1996. 